\title{
The Effect of Interactive Digital Storytelling Gamification on Microbiology Classroom Interactions
}

\author{
Andreea Molnar \\ Lancaster University \\ andreea.molnar@lancaster.ac.uk
}

\begin{abstract}
In this research, we study the use of interactive digital storytelling in teaching microbiology. More specifically, we carried out an exploratory study assessing the effect of using the gamification of an interactive digital storytelling on classroom dynamics and students' interaction. The results show that the presence of gamification led to an increase in classroom discussions and in students' engagement with the learning objectives taught by the interactive digital storytelling.
\end{abstract}

Index Terms - Classroom dynamics, gamification, leaderboard, interactive digital storytelling, microbiology, points, problem based learning, STEM education.

\section{INTRODUCTION}

Science, Technology, Engineering and Mathematics (STEM) fields have experienced recent growth and demand in the workforce. They are also necessary to enhance student's literacy and give them tools to face everyday challenges. However, STEM subjects are often perceived negatively by students and students feel they are not engaging enough [1]. As a result, students often do not engage with the content. One way to engage students is to make the connection between the learning objectives in the classroom and their relation to everyday life. This applies also to Microbiology which is a subject that has many applications in daily life. However, because of the nature of content covered, it is sometimes difficult for students to make the connection between the learning objectives and how they could apply to real life. Interactive digital storytelling could allow students to get familiar with microbiology, provide an overview of the effects in real life and allows students to interact with it and experience the consequences of different decisions.

Digital storytelling "combines the art of telling stories with a mixture of digital media, including text, pictures, recorded audio narration, music and video" [2]. Interactive digital storytelling is digital storytelling that users can control and they can change the story based on their actions. Storytelling has been long used in education and interactive digital storytelling has recently received an increased interest from the research community. Existing research on interactive digital storytelling has focused on the effectiveness in education [3, 4], easing the authoring process [5-7] or ways in which the assessment could be integrated into the storytelling [8]. There is little research on the effect of interactive digital storytelling on classroom interaction. At the same time, while there is substantial research on gamification [9], to the best of our knowledge, little is known about gamification in the interactive storytelling context in particular, and the usage of both interactive digital storytelling and gamification in classroom interaction. In this research, we explore the use of gamification in interactive digital storytelling and how this is affecting classroom interaction.

The rest of the paper is organized as follows. The next section presents the related work focusing on the usage of digital storytelling in education and the existing work on gamification in education. The following section discusses the interactive digital storytelling used in the paper. The succeeding section presents the exploratory study and discusses the results. The last section presents our conclusions and future work.

\section{RELATED WORK}

This section focuses on research on digital storytelling and gamification in education.

\section{Digital Storytelling}

The usage of digital storytelling in classrooms has shown to improve knowledge-based skills [10], higher order skills and understanding $[11,12]$. A study performed by Smeda et al. [13] found that the usage of storytelling in the classroom has helped support student diversity and personalize the student experience. Moreover, it helped create more pleasant learning experiences for students $[14,15]$. The interactivity that interactive digital storytelling provides is motivating and engaging for students [16]. The story helps situate learning in a context [17] while the interaction allows the player to feel in control of their own learning [16].

Most of the use of storytelling for educational purposes is work done in an informal context [18, 19]. In the classroom context, Campbell [20] investigated how digital storytelling could be used as a means of enhancing writing in elementary schools. In this case, the students and teachers were using digital tools as a means of improving classroom 
instruction. The results have been positive showing that it produced better scripts and more sophisticated stories. Sarica and Usluel [21] used pictures and video editing with children to create digital storytelling with positive results. None of the above two studies focused on the usage of an already created interactive digital storytelling to teach or in the classroom interaction.

The research done on the usage of digital storytelling in the classroom found that the classroom became harder to manage and students were disruptive [15] but this study has focused on students creating storytelling rather than using an already created storytelling as a means of learning. However, a different research study has shown positive results (i.e. they help 'break up' the lecturers and improve their attention on the classroom activities) [11].

None of the above studies has explored the use of gamification in an existing interactive digital storytelling aimed on classroom interaction.

\section{Gamification}

Gamification aims to provide a gameful experiences in nongame contexts [22] with the aim of improving user enjoyment [23]. It is believed that the use of gamification in education could motivate and engage students [24], improve learning [25], and increase enjoyment [26]. Christy and Fox [27] used leaderboards for female undergraduate students taking a test and has shown that it could have an effect on the students' academic performance. Although the use of gamification has led mostly to positive outcomes [28], the effects of gamification have not always been necessarily positive. Hanus and Fox [29] showed that long-term students in a gamified course were less motivated, satisfied and empowered than students who took the same course but without the gamification element. Using badges in the classroom has also shown mixed results, with skill badges being beneficial for learning while the participation ones having little effect on engagement [30].

The mixed results of the gamification in the classroom shows that gamification is not a straightforward tool and there is need for further studies to understand how it could be best employed in education. This is a gap this paper aims to address. Moreover, as opposed to the above studies, this research focuses on the effect of interactive digital storytelling gamification on classroom interaction.

\section{INTERACTIVE DIGITAL STORYTELLING}

As a case study, we used an Interactive Digital Storytelling which teaches about microbiology and the importance of handwashing: Global Handwashing Day Game [31]. This is an interactive digital storytelling-based game which teaches microbiology, focusing on microbe transmission and the importance of hygiene. While interacting with the storytelling, the users are taught various learning objectives (see Figure I for an example of the learning objective integrated into the storytelling). The learning objectives covered in the game were based on the European curriculum aimed at secondary school children [32]. The learning objective integration has been done in collaboration with microbiology experts and biology teachers. Some of the learning objectives are repeated through the interactive storytelling to reinforce them but when they are repeated, they are presented to the students in a different context [31].

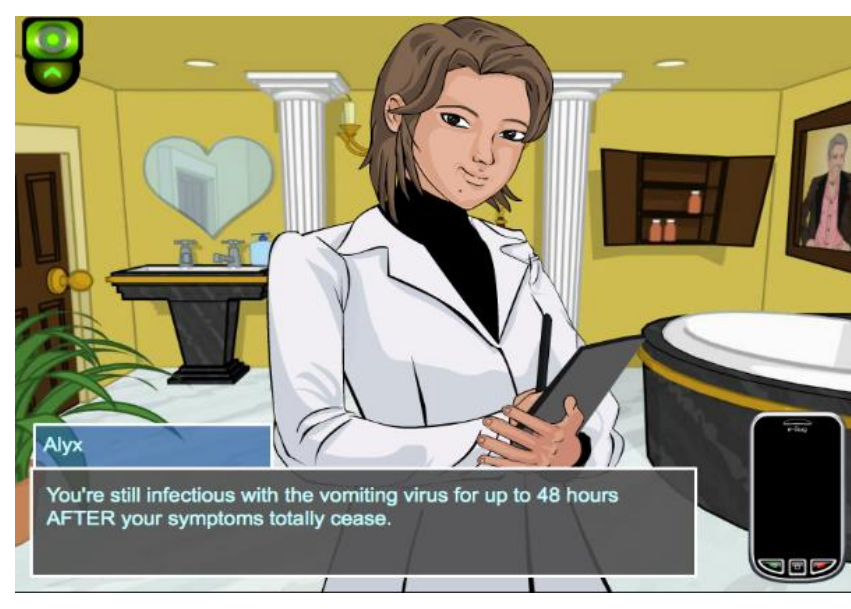

FIGURE I

EXAMPLE OF LEARNING OBJECTIVE TAUGHT THROUGH THE INTERACTIVE DiGITAL STORYTELLING

The storytelling follows a problem based-learning approach [33, 34]. Through the interactive digital storytelling, the player becomes a detective who has to solve a mystery/a problem (i.e. the alleged poisoning of a famous actor). The player is assigned a partner who will help with the game mechanics, but it will also teach or query the player about biology aspects necessary to help with solving the case. The player and his partner try to find the guilty person and through this process, he learns about microbiology and its applications on real life situations. As the storytelling is interactive, the story will change based on the students' actions. This allows not only to customize the storytelling but also the educational content provided based on the knowledge s/he has [6]. The storytelling is over when the guilty party is found, and the player returns to the agency for a debrief. The debrief session is also used as another way to reinforce the learning objective covered through the story. The agency boss asks the user how s/he has solved the mystery. These questions cover not only the steps the player took in the game, but also the learning objective.

Through the interactive digital storytelling, in the dialogue between the player and the other characters in the game, questions that assess students' knowledge are seamlessly integrated [8]. The gamification element has been introduced by giving students points every time they answer a question correctly. At the beginning of the interactive digital storytelling, the users are asked to provide a nickname if they wish this. This is then connected with the points from the game, which are fed back to a leaderboard. On the leaderboard, the students can compare their performance to that of the users. Figure II presents the design of the leaderboard. The players could see their 
nickname (or Anonymous if they did not introduce anything), their score and the date at which the game was played.

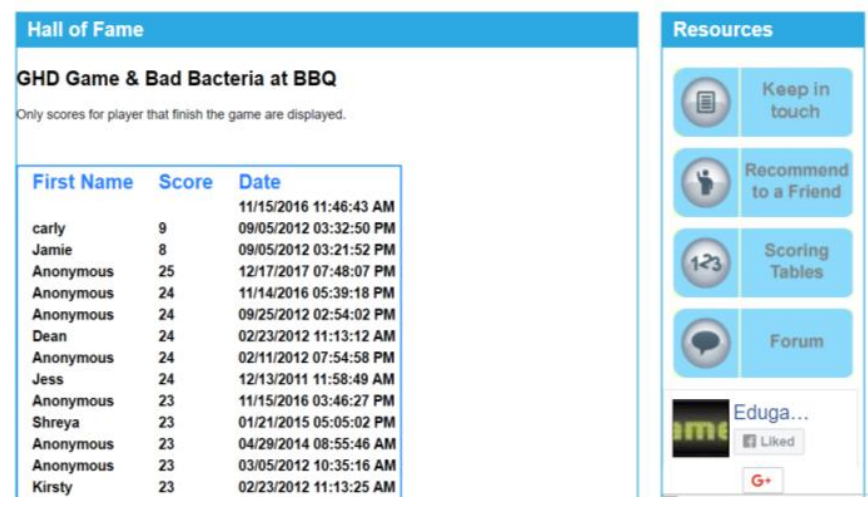

FIGURE II

LEADERBOARD

\section{STUDY AND DISCUSSIONS}

\section{Methodology}

We used two versions of the interactive digital storytelling: one which does not have the gamification and leaderboard element (used by the control group) and another one which had (used by the experimental group). Two classes at a secondary school in the UK use the storytelling during one of their classes. One of these acted as a control group and another one as an experimental group. Solving the mystery takes on average 45 minutes.

\section{Observation}

The results of the study are based on the observations performed by the researchers helping with the study. Observations are especially suited to examine a phenomenon in its natural settings [35], in our case the students using the interactive digital storytelling in the classroom. In the case of the control group, the students read the interactive digital storytelling and interacted with it, but not much interaction was noticed with other classroom members. After finishing the storytelling, the students would move to a different activity or discuss generally the study.

In the case of the experimental group, as soon as one of the students noticed that their answers embedded in the storytelling contributed towards the score and that they could compare their score with others, they started discussing the content covered in the game. Whenever a question in the storytelling will show up from there on, they will debate it and try to find an answer together before providing it in the interactive digital storytelling.

For the control group, although the game had a similar design except for the provided score and leaderboard, the students did not discuss the questions at all. They quietly interacted with the storytelling and were celebrating when they solved the mystery.

Overall, the presence of gamification and the fact that the students could compare their "score" at the end led to anincrease in classroom discussions. The students were more likely to discuss the content as a group when the gamification and the leaderboards were presented while preferring a more individual approach otherwise. Previous research has also shown that when gamification led to a competition-collaboration activity, these are perceived as engaging for the students [36].

Overall, our observation shows that the presence of gamification (score and leaderboard in our case) led to an increase in classroom discussions focused on the learning objectives taught. Although an increase in classroom engagement has been linked in a different context with the increase in student learning [37], this study did not look into this aspect. A bigger sample size will be needed to confirm whether the study could be replicated. The presence of gamification, shows positive results towards engaging the students with microbiology and indirectly it might lead to them better understanding the global challenges in healthcare and how they contribute towards overcoming them.

\section{CONCLUSIONS AND FUTURE WORK}

This article discusses the potential of gamification a classroom situation. It uses one interactive digital storytelling aimed at teaching microbiology at the secondary school level, as a case study. An experimental study was organized with a control group using an interactive digital storytelling game without a gamified element, and another one using a digital storytelling game with a gamified element, which also allowed the use of leaderboards. The exploratory study has shown that the gamification has increased the classroom interaction more than when the gamification was not present.

In our future work, we want to assess the effects of gamification on the number of classroom interaction and how useful these interactions were towards achieving the goal of the class. We also want to look into the effect of gamification (points and leaderboard) not only on classroom dynamics but also on the students' enjoyment and ultimately on the students' academic performance. We also plan to extend the study to a larger sample size and determine whether these findings could be replicated. Indirectly, gamification might be a solution towards lowering the dropout rates, which have occurred when the students used the interactive digital storytelling in informal environments [38]. In our future work, we will analyze whether the user retention rate improves when the storytelling is used in informal learning environments.

\section{ACKNOWLEDGMENT}

Many thanks to the teachers and students who have volunteered to take part in the study. DG SANGO for funding the initial implementation of interactive digital storytelling. Dr. Patty Kotskova for her ongoing support. 


\section{REFERENCES}

[1] Prato, Anthony, Hunter Best, and Isaiah Scurry. 2016. "4th Family STEM program: Sports science." In Integrated STEM Education Conference (ISEC), 2016 IEEE, pp. 102-103. IEEE.

[2] Robin, Bernard R. 2016. "The Power of Digital Storytelling to Support Teaching and Learning." Digital Education Review, 30, pp. 17-29.

[3] Molnar, Andreea, and Patty Kostkova. 2015. "Learning Through Interactive Digital Narratives." Interactive Digital Narrative, pp. 200210.

[4] Padilla-Zea, Natalia, Francisco L. Gutiérrez, José Rafael López-Arcos, Ana Abad-Arranz, and Patricia Paderewski. 2014. "Modeling storytelling to be used in educational video games." Computers in Human Behavior, 31, pp. 461-474.

[5] Markouzis, Dimitris, and Georgios Fessakis. 2016. "Rapid Prototyping of Interactive Storytelling and Mobile Augmented Reality Applications for Learning and Entertainment--The Case of" kKnights"." International Journal of Engineering Pedagogy 6(2), pp. 30-38.

[6] Molnar, Andreea, and P. Kostkova. 2016."Edu-Interact: an authoring tool for interactive digital storytelling based games." Bulletin of the IEEE Technical Committee on Learning Technology 18(2/3), 10-14.

[7] Spierling, Ulrike, and Nicolas Szilas. 2009. "Authoring issues beyond tools." In Joint International Conference on Interactive Digital Storytelling, pp. 50-61. Springer, Berlin, Heidelberg.

[8] Molnar, Andreea, and Patty Kostkova. 2013. "Seamless evaluation integration into IDS educational games." In International Conference on the Foundations of Digital Games. pp. 322-329.

[9] de Sousa Borges, Simone, Vinicius HS Durelli, Helena Macedo Reis, and Seiji Isotani. 2014. A systematic mapping on gamification applied to education. In Proceedings of the 29th Annual ACM Symposium on Applied Computing, pp. 216-222. ACM.

[10] Gregori-Signes, Carmen. 2014. "Digital storytelling and multimodal literacy in education." Porta Linguarum, 22, pp. 237-250.

[11] Taylor, Murray, Mauricio Marrone, Mark Tayar, and Beate Mueller. 2017. "Digital storytelling and visual metaphor in lectures: a study of student engagement." Accounting Education, pp. 1-18.

[12] Yuksel, Pelin, Bernard R. Robin, and Sara McNeil. 2011. "Educational uses of digital storytelling around the world." In Proceedings of International Conference Society for Information Technology \& Teacher Education, 1(1), pp. 1264-1271.

[13] Smeda, Najat, Eva Dakich, and Nalin Sharda. 2014. "The effectiveness of digital storytelling in the classrooms: a comprehensive study." Smart Learning Environments, 1(1), pp. 1-6.

[14] Özpinar, İlknur, Semirhan Gökçe, and Arzu Aydoğan Yenmez. 2017. "Effects of Digital Storytelling in Mathematics Instruction on Academic Achievement and Examination of Teacher-Student Opinions on the Process." Journal of Education and Training Studies, 5(10), pp. 137-149.

[15] Sarıtepeci, Mustafa, and Hasan Çakır. 2017. "Examining Perceived Satisfaction Related to the Digital Storytelling Process." In EdMedia: World Conference on Educational Media and Technology, pp. 11391144. Association for the Advancement of Computing in Education.

[16] Hodhod, Rania, Paul Cairns, and Daniel Kudenko. 2011. "Innovative integrated architecture for educational games: challenges and merits." Transactions on Edutainment, V, pp. 1-34.

[17] Kapp, Karl M. 2012. The Gamification of Learning and Instruction: Game-based Methods and Strategies for Training and Education. John Wiley \& Sons.

[18] Catala, Alejandro, Mariët Theune, Hannie Gijlers, and Dirk Heylen 2017. "Storytelling as a Creative Activity in the Classroom." In Proceedings of the 2017 ACM SIGCHI Conference on Creativity and Cognition (pp. 237-242). ACM.

[19] Garzotto, Franca. 2014. "Interactive storytelling for children: a survey." International Journal of Arts and Technology, 7(1), pp. 5-16.

[20] Campbell, Terry A 2012. "Digital storytelling in an elementary classroom: Going beyond entertainment." Procedia-Social and Behavioral Sciences, 69, pp. 385-393.

[21] Sarıca, Hatice Çıralı, and Yasemin Koçak Usluel. 2016. "The effect of digital storytelling on visual memory and writing skills." Computers \& Education, 94, pp. 298-309.
[22] Deterding, Sebastian, Miguel Sicart, Lennart Nacke, Kenton O'Hara, and Dan Dixon. 2011. "Gamification. using game-design elements in non-gaming contexts." In CHI'11 Extended Abstracts on Human Factors in Computing Systems, pp. 2425-2428. ACM.

[23] Thom, Jennifer, David Millen, and Joan DiMicco. "Removing gamification from an enterprise SNS." In Proceedings of the ACM 2012 Conference on Computer Supported Cooperative Work, pp. 1067-1070. ACM, 2012.

[24] Dicheva, Darina, Christo Dichev, Gennady Agre, and Galia Angelova. 2015. "Gamification in education: a systematic mapping study." Journal of Educational Technology \& Society. 18(3), pp. 75-88.

[25] Alcivar, Isabel, and Andres G. Abad. 2016. "Design and evaluation of a gamified system for ERP training." Computers in Human Behavior 58 pp. $109-118$.

[26] Baxter, Ryan J., D. Kip Holderness Jr, and David A. Wood. 2015. "Applying basic gamification techniques to IT compliance training: Evidence from the lab and field." Journal of Information Systems 30(3), pp. 119-133.

[27] Christy, Katheryn R., and Jesse Fox. 2014. "Leaderboards in a virtual classroom: A test of stereotype threat and social comparison explanations for women's math performance." Computers \& Education, pp. 66-77.

[28] Hamari, Juho, Jonna Koivisto, and Harri Sarsa. 2014. "Does gamification work?--a literature review of empirical studies on gamification." In System Sciences (HICSS), 2014 47th Hawaii International Conference on, pp. 3025-3034. IEEE.

[29] Hanus, Michael D., and Jesse Fox. 2015. "Assessing the effects of gamification in the classroom: A longitudinal study on intrinsic motivation, social comparison, satisfaction, effort, and academic performance." Computers \& Education 80, pp. 152-161.

[30] Caponetto, Ilaria, Jeffrey Earp, and Michela Ott. 2014."Gamification and education: A literature review." In European Conference on Games Based Learning. 1, pp. 51-57. Academic Conferences International Limited.

[31] Molnar, Andreea, and Patty Kostova. 2016. "Interactive Digital Storytelling based educational games: Formalise, author, play, educate and enjoy!-The edugames4all project framework." In Transactions on Edutainment XII (pp. 1-20). Springer, Berlin, Heidelberg.

[32] Lecky, Donna M., Cliodna AM McNulty, Niels Adriaenssens, Tereza Koprivová Herotová, Jette Holt, Pia Touboul, Kyriakoula Merakou et al. 2011. "What are school children in Europe being taught about hygiene and antibiotic use?." Journal of Antimicrobial Chemotherapy 66( suppl_5), pp. v13-v21.

[33] Savery, John R., and Thomas M. Duffy. 1995. "Problem based learning: An instructional model and its constructivist framework." Educational technology 35(5), pp. 31-38.

[34] Farrell, David, Patty Kostkova, Donna Lecky, and Cliodna McNulty. 2009. "Teaching children hygiene using problem based learning: the story telling approach to games based learning." In CEUR Workshop Proceedings, vol. 498. CEUR Workshop Proceedings.

[35] Merriam, Sharan B., and Elizabeth J. Tisdell. 2015. Qualitative research: A guide to design and implementation. John Wiley \& Sons.

[36] Aldemir, Tugce, Berkan Celik, and Goknur Kaplan. 2018. "A qualitative investigation of student perceptions of game elements in a gamified course." Computers in Human Behavior 78, pp. 235-254.

[37] Blasco-Arcas, Lorena, Isabel Buil, Blanca Hernández-Ortega, and F. Javier Sese. 2013. "Using clickers in class. The role of interactivity, active collaborative learning and engagement in learning performance." Computers \& Education 62, pp. 102-110.

[38] Molnar, Andreea, and Patty Kostkova. 2013. "If you build it would they play? Challenges and solutions in adopting health games for children," In Proceedings of ACM SIGCHI Conference on Human Factors in Computing Systems, Let's talk about Failures: Why was the Game for Children not a Success.

\section{AUTHOR INFORMATION}

Andreea Molnar, Dr., Lecturer at the School of Computing and Communications, Lancaster University, UK. 